\title{
Resumo de Tese \\ A utilidade como função para universalidade e eqüidade: uma análise formal da validade instrumental do ordenamento admi- nistrativo federal da assistência à saúde bucal no saúde da família \\ Utility as function for universality and equity: a formal analysis of the instrumental validity of federal administrative ordinance on oral healthcare for the Family Heath Program
}

Carlo Henrique Goretti Zanetti

Trabalho teórico de justificação, desenvolvimento e aplicação de um modelo lógico proposto para realizar, formal e sinteticamente, a avaliação econômica do objeto: a institucionalização do ordenamento administrativo federal da saúde bucal no saúde da família; com o objetivo geral de conhecer e validar sua função de utilidade. A hipótese é que: as condições iniciais que esse ordenamento informa não sinalizam as melhores escolhas para a reorganização da assistência básica prestada pela maioria dos municípios orientados pela estratégia da saúde da família - falta racionalidade ao ordenamento. A justificação teórica pressupôs considerações sobre o ordenamento administrativo como instrumento útil à realização dos princípios constitucionais do SUS; remetendo à idéia instrumental de economia de escolhas em seu sentido filosófico de ordem, no plano político do contrato social; bem como em seu sentido técnico mais aplicado de utilidade, no plano da realpolitik das ações da administração pública. Recorreu-se a uma metodologia racional-dedutiva: (i) fazer a descrição fundamental; (ii) investigar a heurística e sintaxe da formalização dos programas possíveis sob tal ordenamento; (iii) explorar, aos limites, os procedimentos de representação de ordem mediados pelas categorias econômicoutilitárias de eficácia (potência) e eficiência (rendimento); (iv) fazer julgamentos; (v) proferir prescrições normativas úteis (recomendações). A aplicação do modelo, orientada nos princípios constitucionais de universalidade e eqüidade, pressupôs duplo julgamento: (i) da eficácia do ordenamento para a universalidade ajuizada no valor normativo da igualdade; (ii) da eficácia e eficiência do ordenamento para eqüidade ajuizada no valor normativo da diferença. Eficácia e eficiência consideradas no plano administrativo; e, igualdade e diferença no plano do contrato. Principais resultados: (i) apenas 20,36\% dos municípios que aderiram às regras federais têm potência nominal (eficácia) para assegurar acesso universal; (ii) apenas 6,88\% apresentam eficácia em condições favorecidas para eficiência; (iii) somente $0,2 \%$ apresentam eficácia em condições desfavorecidas para eficiência e justificáveis por razões de justiça. Principal conclusão: formalmente, o ordenamento vigente é inútil em termos racionais e não-razoável em termos de justiça, portanto, nacionalmente inválido para reorientar a assistência básica em saúde bucal na observância dos princípios constitucionais de universalidade e eqüidade. Principal recomendação: na impossibilidade de um arranjo alocativo capaz de reunir simultaneamente virtudes utilitárias e de justiça, há que se adotar duas regras: uma que sinalize eficácia e eficiência ótima para sistemas locais que contam com condições iniciais mais favorecidas; e, outra que sinalize eficácia, eficiência subótima para sistemas em condições menos favorecidas. Ambas estribadas nas razões práticas de utilidade e justiça.

Palavras-chave: Serviços de Saúde Bucal-economia; Saúde da Família; Economia da Saúde.
Key Words: Dental Health Services-economics; Family Health; Health Economics. 


\section{Tese de Doutorado}

\section{Nome do Orientador}

Maria Helena Machado

Escola Nacional de Saúde Pública /

Fundação Oswaldo Cruz

Rio de Janeiro, 2005.

\section{Disponível no Portal de Teses Fiocruz:}

http://www.bvssp.cict.fiocruz.br/lildbi/docsonline/7/1/

617-zanettichgd.pdf 